\title{
Double Perspective Data Envelopment Analysis: One Approach to Estimate the "LOOP" Arbitrage
}

\author{
Luiz Fernando de Lyra Novaes, Sérgio Antâo Paiva
}

${ }^{1}$ D Sc Production Engineering, Avalsoft, Brazil; ${ }^{2} \mathrm{M}$ Sc Regional \& Urban Planning, Caixa Economica Federal, Federal Savings Bank, Brazil.

E-mail: luiz@avalsoft.com.br, sergio.paiva@caixa.gov.br

Received July $17^{\text {th }}, 2010$; revised August $18^{\text {th }}, 2010$; accepted October $2^{\text {nd }}, 2010$.

\begin{abstract}
This paper introduces the application of real estate pricing DP DEA - Double Perspective Data - Envelopment Analysis to solve the LOOP (Law of One Price) arbitrage. A general equilibrium model of real estate values was developed to analyze price variation over digital map, and applied to the urban area of the city of Joinville. The power of real estate locational value assessment using DP-DEA is then compared with the usual MRA - Multiple Regression Analysis using a real case of land data. All computational generated results and data were subsequently geocoded on a GIS - Geographic Information System. The computational generated Price line Map is easily visualized in a real estate value chart that can enhance accuracy when compared to a conventional methodology, also a tool for immediate updates and testing the effects of new developments over urban areas.
\end{abstract}

Keywords: Double-Perspective Data Envelopment Analysis, Law of One Price, Spatial Model and GIS

\section{Introduction}

In this paper, the DP-DEA (Double Perspective - Data Envelopment Analysis) [1] is applied in order to establish the LOOP (Law of One Price) [2] arbitrage for estimating property taxes value.

Kuosmanen et al. [3] approached an application with LOOP-based weight restrictions incorporated in Data Envelopment Analysis, utilizing the relation between the industry level and the firm level cost efficiency measures, they propose to apply a set of input prices that is common for all firms and that maximizes cost efficiency of the industry. The proposed methodology was utilized to the evaluation of the research efficiency of economics departments of Dutch Universities.

The LOOP's main principle states that when assets are identical in all aspects of value or characteristics, they must have the same price under market equilibrium. If two identical assets have different prices, there will exist an arbitrage opportunity and exploring this opportunity will help ensuring that prices of the two assets converge.

An asset's fundamental value is the price that wellinformed investors must pay in a free and competitive market. By the Law of One Price investors would assess values such that equivalent assets have the same price. There can be a temporary difference between the market price of an asset and its fundamental value. Likewise, security analysts make their living by researching the prospects of various firms and recommending which stocks to buy, because their price appears low relative to fundamental value, and which to sell, because their price seems high relative to fundamental value.

Baye et al. [4] says: although, simple textbook models of competitive markets for homogeneous products suggest that all-out competition among firms will lead to the law of one price. Yet, empirical studies spanning more than four decades reveal that price dispersion is the rule rather than the exception in many homogeneous product markets.

More clearly, this occurs to the heterogeneous real estate market. At despite of this to investment decisions, there are many other situations in which you may need to determine the value of an asset. Suppose that the tax assessor in your town has assessed your house at $\$ 490,000$ for property tax purposes. Is this value too high or too low?

In the real estate market it is stated that no two distinct assets are identical in all aspects. Always, some difference of characteristics exists, maybe the localization, configuration or the size of the lot and the house or something else. The process of valuation requires that we 
find assets comparable to the one whose value we want to estimate, and make judgments about which differences are important on their value to investors. This specific market equilibrium point is achievable when buyer and seller engaged in a dispute have attended their own interests of all kinds on the value of a specific real estate.

Valuation information is fundamental to financial decision-making. Our goal in real estate assessment is to estimate a value of a spread range between the maximum value and the minimum value offered or bided in an efficient property market.

\section{Tax Assessment}

The Direct Capital Comparison (DCC) is the most conventional method used in real estate value appraisal (see Mackmin (1994), for instance). DCC requires an "allowance in money terms" (Lewis (1999)) for any differences between the subject property and the comparable properties, for which the appraiser can employ either multiple regression analysis (MRA), expert systems (ES) or artificial neural networks (ANN). The most usual method established is the MRA that's diffused between the professional's experts.

The tax assessment problem consists in establishing a mean value of tax that will apply over different properties. Nowadays, in spatial models DCC and GIS data basis are used.

The question is to consider valuing a house using the observed prices of comparable houses. Suppose that you own a house and that each year you pay property taxes to the local town council, which are computed as a proportion of the house estimated market value. You have just received a notice from the town's real estate assessor notifying you that the estimated market value of your house this year is $\$ 490,000$.

Suppose that your next-door neighbors just sold a house identical to yours for $\$ 330,000$. You could justifiably appeal the town's assessment of $\$ 490,000$ for the value of your house being too high, on the grounds that a house virtually identical to yours was just sold for a price $\$ 160,000$ less than your assessed value.

In the valuation of your house, you are applying the Law of One Price, considering that if you were to put the house up for sale, you are implying that your expectation is that it would fetch a price of $\$ 330,000$ because a comparable house just sold for that amount.

Of course, the house next door is not exactly identical to yours because it is not located on your lot but on the one next to it. And you probably cannot prove that if you actually put your house up for sale it would fetch only $\$$ 330,000 rather than the $\$ 490,000$ that the town's assessor says it is worth. Nonetheless, unless the town's assessor can point to some economically relevant feature of your house that would make it worth $\$ 160,000$ more than your neighbor's house (such as more land or floor space), you would have a strong logical case (and probably a strong legal case, too) for appealing the town's assessment.

The point is that even when the force of arbitrage cannot be relied on to enforce the Law of One Price, we still rely on its logic to value assets.

But how did the assessor place a value on your house? Because you will have to pay taxes based on his assessment, the assessor must choose a valuation method that is perceived as fair and accurate. Valuation models used in real estate assessment vary significantly in their level of complexity and mathematical sophistication.

Property tax, or millage tax, is an ad valorem tax that an owner is required to pay on the value of the property being taxed. Property tax can be defined as generally, tax imposed by municipalities upon owners of property within their jurisdiction based on the value of such property. There are three species or types of property: Land, Improvements to Land (immovable manmade objects; i.e., buildings), and Personal (movable manmade objects). Real estate, real property or realty is all terms for the combination of land and improvements. The taxing authority requires and/or performs an appraisal of the monetary value of the property, and tax is assessed in proportion to that value. Forms of property tax used vary between countries and jurisdictions.

The property tax (ad valorem tax) relies upon the fair market value of the property being taxed for justification. In Brazil, it's often given to property tax a value per square meter. To calculate the property tax for a lot, the authority will multiply the assessed unit tax value of the property by its area.

We developed a LOOP DP DEA on a Spatial Model to a housing data set from Joinville, Santa Catarina, Brazil. The County Department is responsible for complying with Brazilian fiscal responsibility law that improves public finance rules while enforcing responsibility in fiscal management. That presumes well-planned and transparent actions to prevent social risk and correct deviations that may affect the equilibrium of public accounts. This law is a major obligation to be achieved. In that way, the town's assessors have to establish equitable and fair values to different real estates.

\section{LOOP/DP-DEA}

A new approach is being proposed to solve LOOP arbitrage, where the uncertainty in the unit's value resulting from market transactions was taken into account by explicitly representing the economic agents involved in a transaction, namely buyer and seller, whose actions establish a set of transactions. Because of its non-linear 
structure, the proposed method performs better than regression analysis, in terms of adhering to data information, as shown in Subsection 3.2. Concerning ES and ANN, the new method overcomes an important weakness, as it offers model parameters, i.e., the weights assigned to each input, thus facilitating the cognitive reasoning process. However, the major advantage of this method consists in supplying a reference set for comparison with the assessed property, a characteristic directly linked to DCC philosophy and which is not provided by any other method so far.

The methodology to achieve this was named Law of One Price by Double Perspective-Data Envelopment Analysis (LOOP/DP-DEA). The DP-DEA makes use of two encapsulating surfaces that enfold, in an n-dimensional space, all the observed data. Real estate units which, from the point of view of either the seller or the buyer, present an "efficient" price, define those surfaces. The remaining units can have their value assessed by taking the envelopments as frameworks, under an output-oriented or an input-oriented DEA model. The LOOP/DP-DEA is the market value estimated between the two encapsulating surfaces, which minimize the median absolute deviation of the whole distribution.

This methodology intends to make a contribution to the real estate community in three different ways: firstly, by introducing the concept of the LOOP/DP-DEA used to estimate the fundamental value; secondly, by showing how this concept can be applied in real terms, namely the real estate value assessment problem; and thirdly by suggesting that the idea of the two enveloping surfaces can be brought to the more general context of economic/ financial transactions, taxation, urban planning or even auctions.

The specific application of DP-DEA to real estate tax assessment can have wide impact in county public institutions involved on regulation and taxation, dealing with many daily decisions concerning county administration. If a more precise tool is available, these institutions would be able to achieve a much more reliable portfolio of taxation and, therefore, attending a well-planned public administration.

In recent years, GIS has established itself as an integral component of business improvement programs at government agencies and utilities, it has sparked flashes of interest from the utility of visualizing the analysis results. In that way, assuring for the analyst a powerful instrument to better understood. New emphasis on reengineering bodes well for commercial GIS, however, and this trend could trigger GIS' ascent to a more prominent spot in corporate decision-making tools in Brazil. On this propose we apply the value estimation made by MRA, DP-DEA and real estate data over a geographic data ba- sis of Joinville and analyze them comparatively. The comparison of each estimated isolines formed by the regions with the same taxes value per square meter. The isolines join points of equal value on a surface geographic map. The shading defines bands between two succeeding isolines. In our study case, they decrease of value on the inside to the outside of the map.

\subsection{Double Perspective DEA Model - DP-DEA}

The DEA method is used to accomplish comparative analyses of a set of observations. For each observed unit, either a State in a national economy or a simple piece of equipment, it provides a measure of efficiency or productivity. DEA is a generalization of the nonparametric method of productivity measurement originally developed by Farrell [5].

The first classical DEA model was the CCR proposed by Charnes, Cooper and Rhodes [6], also known as CRS because it assumes Constant Returns to Scale. The second one was the BCC introduced by Banker, Charnes and Cooper [7], or VRS, as it postulates Variable Returns to Scale. Shortly, the method works as follows [8]. Some applications and integration perspectives in Decision Support Theory may be seen in Lins et Meza [9].

The DP-DEA is an extension of Data Envelopment Analysis [10]. This approach has been able to assess a particular real estate, or for a general assessment, estimated by market's data. The mathematical formulation of the DP-DEA method makes it possible to obtain an interval for a property's value as a function of its physical features and location, as proposed by Novaes [1].

In this paper the DP-DEA method was applied to a database consisting of the market values of lots that were established in real estate transactions or offers, and which have occurred in several neighborhoods in the city of Joinville. This data basis was been performed by the Joinville Municipal Treasurer Department. The buy and sell bids for the different units define the supply and demand possibilities as a function of the commodities' attributes [11].

Double Perspective DEA (DP-DEA) uses as an objective measure of the observed units the normalized distance to the two simultaneous perspectives: the hyper planes by maximization of outputs and by the minimization of inputs, in such a way that inputs under a buyer's perspective are the outputs under the seller's perspective and vice-versa. Property value is the dependent variable estimated by the MRA method when applied to real estate assessment. Analogously, in LOOP DP-DEA we will estimate the dependent variable, which is the property value: the monetary amount received (output of the transaction on a seller's perspective) and the monetary amount paid (input of the transaction on a buyer's per- 
spective). The property's physical features are the input of the transaction on seller's perspective and the output of the transaction on buyer's perspective. In LOOP DP-DEA, like in MRA method, they are the independent variables.

The method employs both classical CRS and VRS DEA models. Starting from the selection of $\mathrm{n}$ observed real estate data, with $\mathrm{m}$ independents variables like localization and s dependent variable, a DP-DEA model determines a subset composed of $\mathrm{k}$ data that belongs to the perspective's enveloping surface. These data are considered the best to attend one or other perspective and define the segments of the enveloping surface, thus motivating the envelope form of DEA CCR or BCC models. The contained subset, not belonging to this surface, is formed by the remaining $\mathrm{n}-\mathrm{k}$ inefficient data to each perspective. The computation of the normalized distance of each observed unit requires the solution of a linear programming problem. To estimate the value of the dependent variable, we have to multiply the observed value by the result $\mathrm{Z}$ of equation 28 which minimizes the median absolute deviation of the whole distribution.

The formulation of DP-DEA in their dual multipliers/envelope output-oriented is the same of the both classical CCR and BCC DEA models, shown in Table 1. In the multipliers model, the optimal values of the decision variables: $\mathrm{v}, \mathrm{u}$ and $\mathrm{u} 0 *$ are the parameters of the frontier hyper plane defined by the constraints (3). They are finding such that the distance measure for observed data

Table 1. Output-oriented CCR and BCC models.

\begin{tabular}{l} 
Multipliers (Primal) \\
Min $L_{0}=\sum_{i=1}^{m} \varpi_{i} x_{i 0}+u_{0}^{*}$ \\
Subject to $\quad \sum_{r=1}^{s} \mu_{r=} y_{r 0}=1$ \\
$-\sum_{r=1}^{s} \mu_{r} y_{r j}+\sum_{i=1}^{m} \varpi_{i} x_{i j}+u_{0}^{*} \geq 0 \quad j=1, \ldots, n$ \\
$\mu_{r} \geq \varepsilon, \quad r=1, \ldots \ldots, s, \quad \varpi_{i} \geq \varepsilon \quad i \quad=1, \ldots ., m$ \\
$\varpi_{i}, \mu_{r}>0, \quad \forall i, r$ \\
For $C C R: u_{0}^{*}=0$ \\
\hline Envelopment $($ Dual) \\
\hline Max $H_{S}=h_{S}+\varepsilon \sum_{y=1}^{s} s_{y}^{+}+\varepsilon \sum_{x=1}^{r} s_{x}^{-}$ \\
Subject to $h_{s} y_{r 0}-\sum_{j=1}^{n} \lambda_{j} y_{r j}+s_{r}^{+}=0, \quad r=1, \ldots \ldots ., s$ \\
$-x_{i 0}+\sum_{j=1}^{n} \lambda_{J} x_{i j}+s_{i}^{-}=0, \quad i=1, \ldots \ldots, m$ \\
$\lambda_{j}, s_{r}^{+}, s_{i}^{-} \geq 0, \forall k, j, i$ \\
For $B C C: \sum_{j=1}^{n} \lambda_{j}=1$ \\
\hline
\end{tabular}

"O" is minimized. This distance can be defined as a programming problem that minimize the linear combination of its independents variables (1) subject to the constraints: the normalized linear combination of its dependents variables (2) and that all distance measures must be plus than or equal to one (3). Non-Archimedean constrained multipliers (4) can be a substitute for classical positive constrained multipliers (5), where is an infinitesimal (non-Archimedean) amount.

According to the envelope form, the problem consists of maximizing the objective function (7) on the decision variable $\mathrm{h} \mathrm{S}(1 / \mathrm{h} \mathrm{S}$ represents the normalized distance to the hyper-plane) subject to constraints (8) to (11). These constraints guarantee that the projected efficient unit in seller's perspective will be located inside the production or demand possibilities set, which is defined as a linear combination of the outputs (and inputs) vectors, using the coefficient vector. In accordance to the BCC assumptions, this linear combination should be subjected to a convex constraint (11), which does not hold in the CCR model. The inclusion of this latter constraint in BCC corresponds to an unconstrained dual variable (6) in the multipliers model.

Analogously, to the classical input-oriented dual multipliers/envelope CCR and BCC models the variables and constraints are quite similar; the main difference being that in the multipliers model the objective is to maximize the linear combination of the outputs of the observed data, keeping the independent variables normalization constraint. As for the envelope form, the variable $h$ is to be reduced, and multiplied by the input of the assessed (observed) unit [6,7].

As Figures 1 and 2 illustrate, considering only one input and one output (either the maximum or the minimum values of the units' sale and only one attribute, i.e., their areas).

In order to simultaneously use both input and output oriented models, we will transpose the graph of the input-

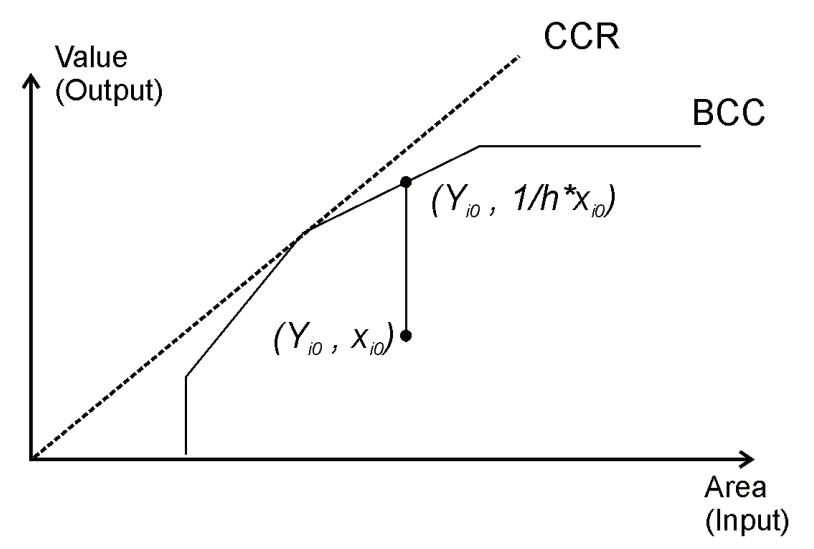

Figure 1. Output-oriented model. 
oriented model in Figure 2 to obtain, in Figure 3, the same axes as in the output-oriented model of Figure 1.

The input-oriented model transposed is resulted of the transposition of the classical input-oriented dual multipliers/envelope CCR and BCC model demonstrated in Table 2.

The formulation of DP-DEA in their dual multipliers/envelope input-oriented shown in Table 2 is result of the transposition of the both classical CCR and BCC DEA models. In the multipliers model, the optimal values of the decision variables: $\mathrm{v}, \mathrm{u}$ and $\mathrm{w} 0^{*}$ are the parameters of the frontier hyper plane defined by the constraints (14). They are finding such that the observed DATA " 0 " is maximized. This distance can be defined as a programming problem that maximizes the linear combination of its independents variables (12) subject to the constraints: the normalized linear combination of its dependents variables (13) and that all distance measures must be less than or equal to one (14). Non-Archimedean constrained multipliers (15) can be a substitute for classical positive constrained multipliers (16), where is an infinitesimal (non-Archimedean) amount.

According to the envelope form, the problem consists of minimizing the objective function (18) on the decision variable $h_{B}$, subject to constraints (19) to (22). These constraints guarantee that the projected efficient unit in Buyer's perspective will be located inside the demand possibilities set, which is defined as a linear combination of the outputs (and inputs) vectors, using the coefficient vector. In accordance to the $\mathrm{BCC}$ assumptions, this linear combination should be subjected to a convex constraint (22), which does not hold in the CCR model. The inclusion of this latter constraint in BCC corresponds to an unconstrained dual variable (17) in the multipliers model.

Figure 4 shows the two graphs put together. The space defined by the enveloping surfaces corresponds to a set of accomplished transactions [10]. It results from the intersection of the set of supply possibilities $[12,13]$ Shephard [14], and the set of demand possibilities. In other words, the DP-DEA defines supply and demand frontiers. Formally, it is possible to devise the DP-DEA model as a classic DEA output-oriented model together with an input-oriented model with the transposition of an axis, as shown in Figure 4.

The software EDODEA [15] assesses the projected efficient unit on buyer's and seller's perspective enveloping surfaces.

\subsection{Law of One Price by Double Perspective Data Envelopment Analysis - LOOP/DP-DEA}

The software $E D O D E A$ assesses the dependent variables

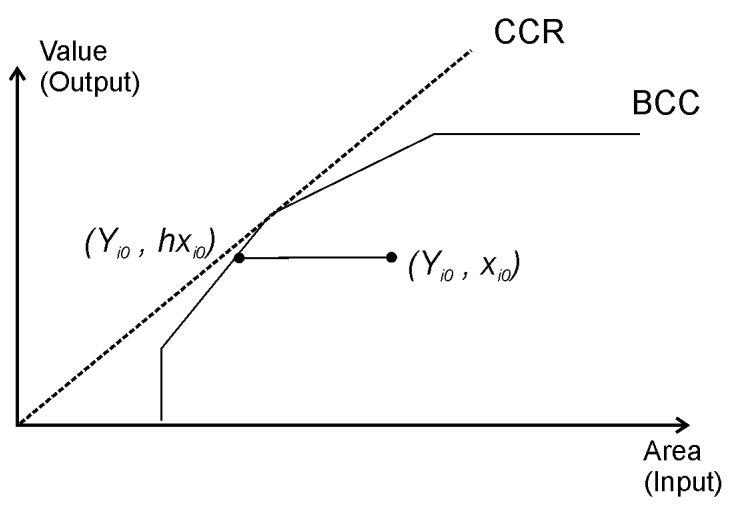

Figure 2. Input-oriented model.

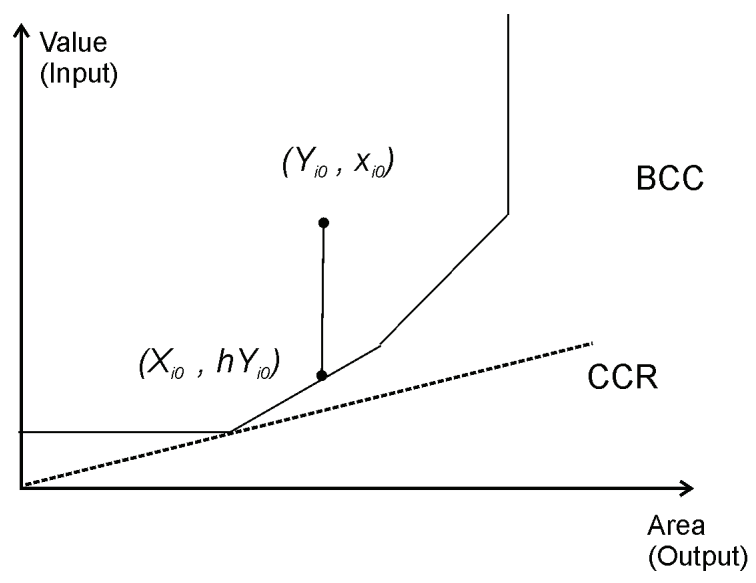

Figure 3. Input-oriented model (transposed).

Table 2. Input-oriented CCR and BCC models transposed.

\begin{tabular}{|c|c|}
\hline \multicolumn{2}{|l|}{ Multipliers (Primal) } \\
\hline $\operatorname{Max} Z_{0}=\sum_{i=1}^{m} v_{i} x_{i 0}+w_{0}^{*}$ & (12) \\
\hline Subject to $\sum_{r=1}^{s} u_{r} y_{r 0}=1$ & (13) \\
\hline$-\sum_{i=1}^{m} v_{i} x_{i j}+\sum_{r=1}^{s} u_{r} y_{r j}+w_{0}^{*} \geq 0 \quad j=1, \ldots, n$ & (14) \\
\hline$u_{r} \geq \varepsilon, \quad r=1, \ldots \ldots, s, \quad v_{i} \geq \varepsilon \quad i=1, \ldots, m$ & $(15)$ \\
\hline$u_{r}, v_{i}>0, \quad \forall i, r$ & (16) \\
\hline For $C C R: w_{0}^{*}=0$ For BCC: $w_{0}^{*}$ unconstrained & (17) \\
\hline \multicolumn{2}{|l|}{ Envelopment (Dual) } \\
\hline $\operatorname{MinH}_{B}=h_{B}+\varepsilon \sum_{y=1}^{s} s_{y}^{+}+\varepsilon \sum_{x=1}^{r} s_{x}^{-}$ & (18) \\
\hline Subject to $h_{B} y_{r 0}-\sum_{j=1}^{n} \lambda_{j} y_{r j}-s_{r}^{-}=0, \quad r=1, \ldots \ldots, s$ & (19) \\
\hline$x_{i 0}-\sum_{j=1}^{n} \lambda_{J} x_{i j}+s_{i}^{+}=0, \quad i=1, \ldots \ldots, m$ & (12) \\
\hline$\lambda_{j}, s_{r}^{+}, s_{i}^{-} \geq 0, \forall k, j, i$ & (21) \\
\hline ForBCC $: \sum_{j=1}^{n} \lambda_{j}=1$ & $(22)$ \\
\hline
\end{tabular}




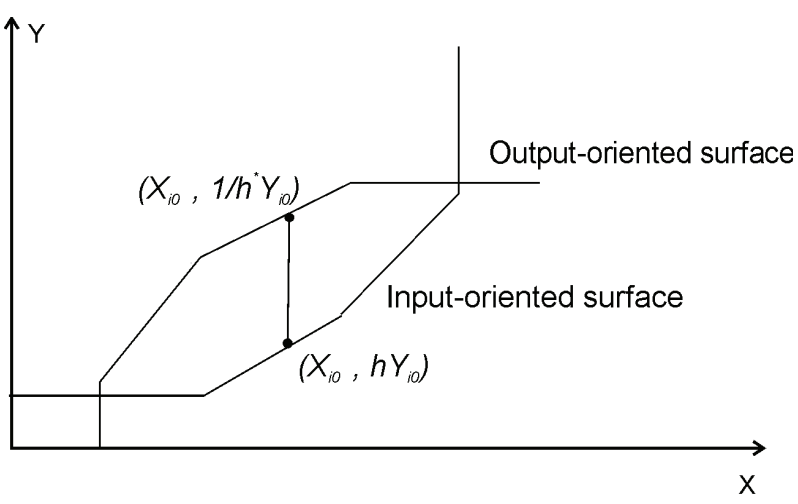

Figure 4. Double perspective DEA method.

$\Phi j$ by the minimization of the median absolute deviation of the whole distribution determined by the escalate $\mathrm{Z}$, the formulation is:

$$
\begin{aligned}
& \sum_{j=1}^{n}\left(\varphi_{j}-y_{j}\right)=0 \\
& \varphi_{j}=Z\left(y_{S j}-y_{B j}\right)+y_{B j} \\
& \varphi_{j} \geq 0 \quad Z \geq 0
\end{aligned}
$$

By Seller's Perspective $y_{S j}=y_{j} / h_{S j}$

By Buyer's Perspective $y_{B j}=y_{j} \times h_{B j}$

$$
Z=\frac{\sum_{j=1}^{n} y_{j}-\sum_{j-1}^{n} h_{B j} \times y_{j}}{\sum_{j=1}^{n}\left(\frac{1}{h_{S j}}-h_{S j}\right) \times y_{j}}
$$

Notation

$\varphi_{j} \quad$ Real estate j price assessable

$y_{S j} \quad$ Projected value of data $\mathrm{j}$ on the enveloping surface on seller's perspective

$y_{B j} \quad$ Projected value of data $\mathrm{j}$ on the enveloping surface on buyer's perspective

$y_{j} \quad$ Real estate $\mathrm{j}$ price observed

Z escalate

$h_{S j} \quad$ Real estate assessed $\mathrm{j}$ deviations to the enveloping surface on seller's perspective

$h_{B j} \quad$ Real estate assessed $\mathrm{j}$ deviations to the enveloping surface on buyer's perspective

The LOOP/DP-DEA piece-wise line on R2 is illustrated in Figure 5, applying all possible variation of $\varphi_{j}$ by Equation (24).

\section{Conclusions}

Applying on the software EDODEA, the data basis of two papers Novaes et Paiva [1] and [16], we obtain respectively:

$$
Z(2004)=0,41045 \text { and } Z(2006)=0,2739
$$

The results of MRA and DP-DEA medium value obtained in Novaes et Paiva [16] paper are related on Table 3 and compared with the news results obtained by the applying to LOOP/DP-DEA.

The results obtained in Novaes et Paiva [1] paper are related on Table 4 and compared with the new results obtained by the applying to LOOP/DP-DEA.

Comparison of results on Tables 3 and $\mathbf{4}$ indicates deviations with best results on estimating with LOOP/DPDEA method.

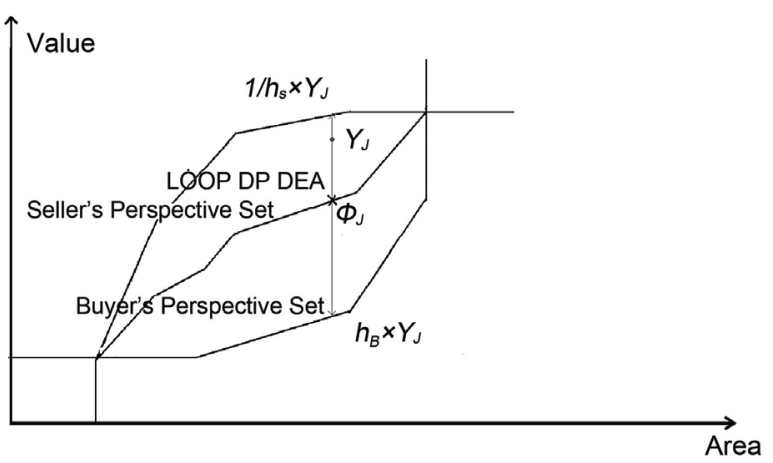

Figure 5. $\phi_{J}$ The piece-wise line-LOOP DP-DEA.

Table 3. The results of MRA and DP-DEA medium value in Novaes et Paiva [1].

\begin{tabular}{cccc}
\hline $\begin{array}{c}\text { Statistical Analysis } \\
\text { of deviations }\end{array}$ & $\begin{array}{c}\text { Multiple } \\
\text { Regression } \\
\text { Analysis }\end{array}$ & $\begin{array}{c}\text { DP-DEA } \\
\text { medium value }\end{array}$ & $\begin{array}{c}\text { LOOP/DP-D } \\
\text { EA }\end{array}$ \\
\hline Medium deviations & 0,00 & $-105,27$ & 0,01 \\
$\begin{array}{c}\text { Total sum of } \\
\text { deviations }\end{array}$ & 1,14 & $-26.633,65$ & 1,57 \\
$\begin{array}{c}\text { Total sum of squares } \\
\text { of deviations }\end{array}$ & $54.794 .462,34$ & $17.965 .031,42$ & $7.534 .440,88$ \\
\hline
\end{tabular}

Table 4. The results of MRA and DP-DEA medium value in Novaes et Paiva [16].

\begin{tabular}{cccc}
\hline $\begin{array}{c}\text { Statistical } \\
\text { Analysis } \\
\text { of deviations }\end{array}$ & $\begin{array}{c}\text { Multiple } \\
\text { Regression } \\
\text { Analysis }\end{array}$ & $\begin{array}{c}\text { DP-DEA } \\
\text { medium value }\end{array}$ & LOOP/DP-DEA \\
\hline $\begin{array}{c}\text { Medium } \\
\text { deviations }\end{array}$ & 0,01 & $-1.372,30$ & 0,00 \\
$\begin{array}{c}\text { Total sum of } \\
\text { deviations }\end{array}$ & 1,31 & $-351.309,63$ & $-0,01$ \\
$\begin{array}{c}\text { Total sum of } \\
\text { squared } \\
\text { deviations }\end{array}$ & $13.699 .082 .578,10$ & $8.905 .893 .694,13$ & $8.139 .847 .100,39$ \\
\hline
\end{tabular}


The software ArcGIS Desktop lets perform full range from a geodatabase design and management to editing from map query to cartographic production and sophisticated geographic visualization and analysis. When you add a dataset to a map, a layer is created. In the course of making your maps, you'll add and remove layers, turn them on and off, changing the draw order, and so on, to display exactly the data you need to see and work with.

When you add a dataset to a map, the software draws all the features using the same symbol. Often you'll want to draw the data symbolized by an attribute value (almost the case for continuous areas). The symbol used to draw each feature (the marker size, continuous line, or area color fill, for example) is determined by the value of a feature for a particular attribute.

Our case study, applied in the Arcview architecture, over a geographic data set on Joinville map, the land value per square meter of a property tax estimated by each method: MRA and both DP-DEA methods are geocoded in coordinate system UTM-Universal Transverse Mercator SAD 69. In an easy view, we compared then with the observed data. The technical named ordinary kriging produce from each point geocoded with the same value a linkage and an interpolation in a continue surface by the variance between of the estimated or observed values $[17,18]$.

These applications result on four cartographic layers, Figures 6 to 9, that possibility an analysis of the accuracy on estimation of each method. It possibility the comparative overview analysis, on how the isolines surface seems more adjustable with the Figure 6, that is the performed by a collection of a County cartographic lot tax rates geocoded data basis. The defined isolines delimit areas with the same estimated value, which in practice represents the land value per square meter for a block. The geographic Figure 6 represents the variations of real estate value observed; Figure 7 represents the variations of land value estimated by MRA; Figure 8 represents the variations of lands by DP-DEA medium value, and; Figure 9 represents the variations of lands by LOOP/DP-DEA. The outside isolines to inside have the range variations of lands value per square meter of $\$ 0$ to $\$ 25,00 ; \$ 25,00$ to $\$ 50,00 ; \$ 50,00$ to $\$ 100,00 ; \$ 100,00$ to $\$ 200,00 ; \$ 200,00$ to $\$ 400,00 ; \$ 400,00$ to $\$ 800,00$, and more than $\$ 800,00$.

Visualizing the Figure 9 we conclude that the map with the isolines estimated by LOOP/DP-DEA is closer to the real estate original value isolines represented in Figure 6. In conclusion, LOOP/DP-DEA method in this case is more accurate to estimate real estate value than MRA method.

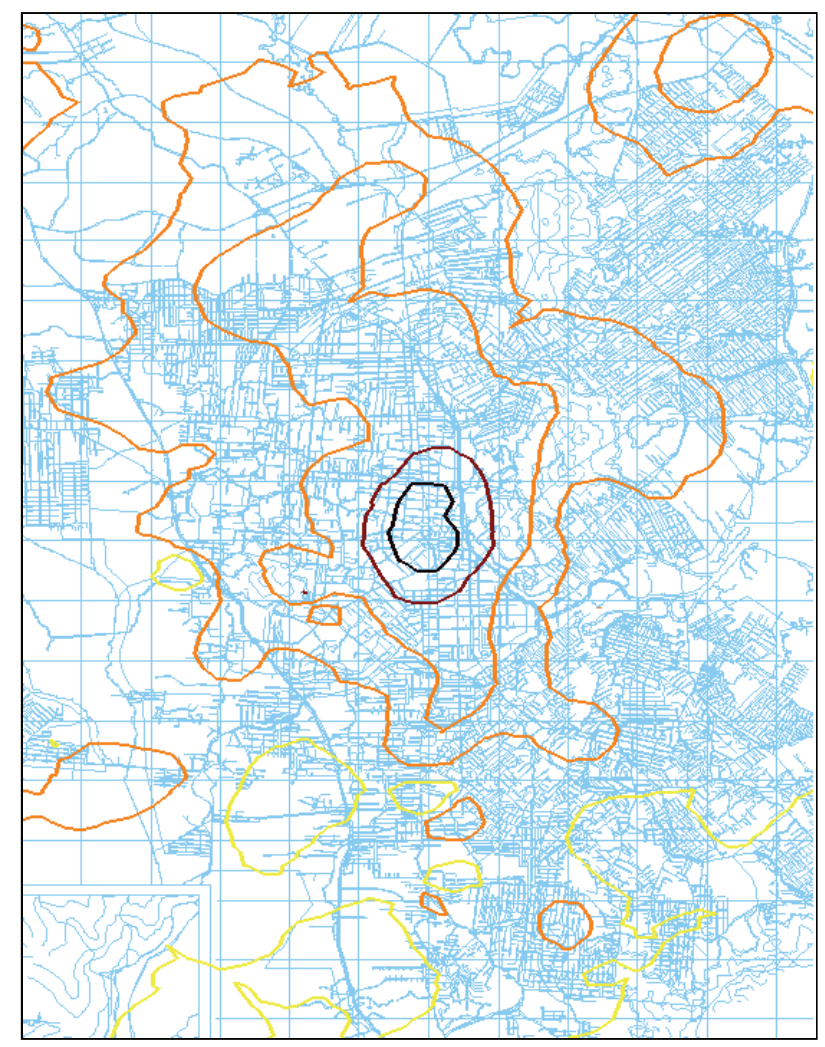

Figure 6. Real estate value.

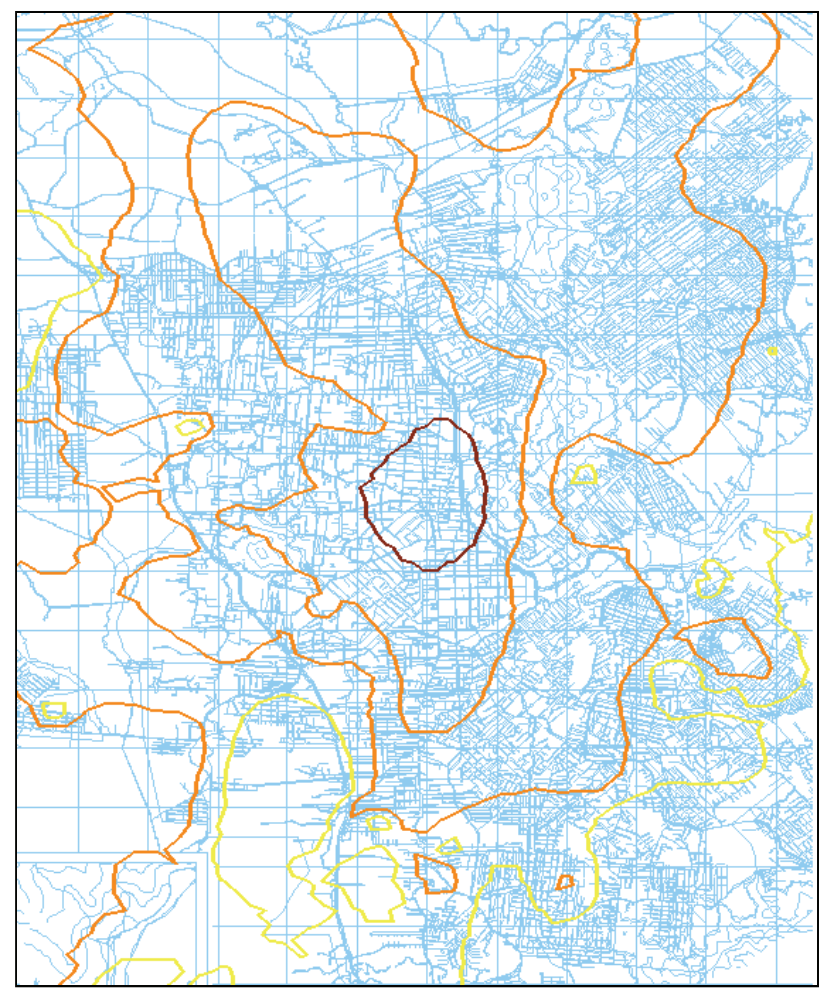

Figure 7. Real Estate Value estimated by MRA (Multiple Regression Analysis). 


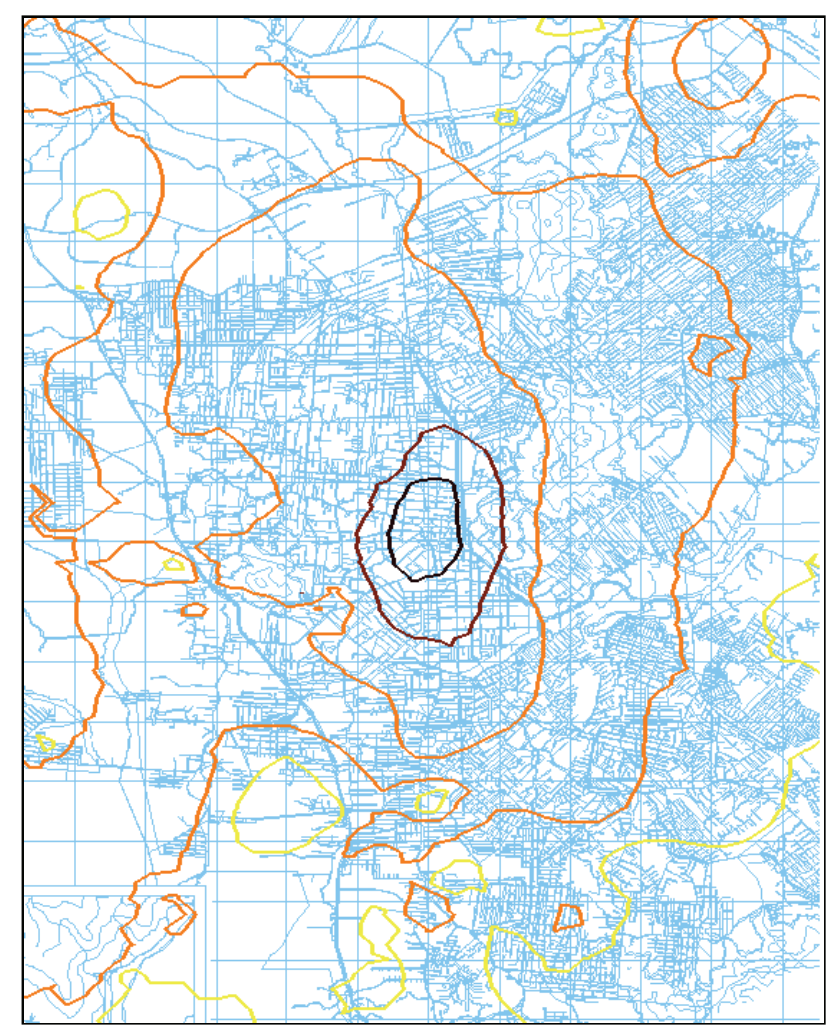

Figure 8. Real estate value estimated by DP-DEA medium value.

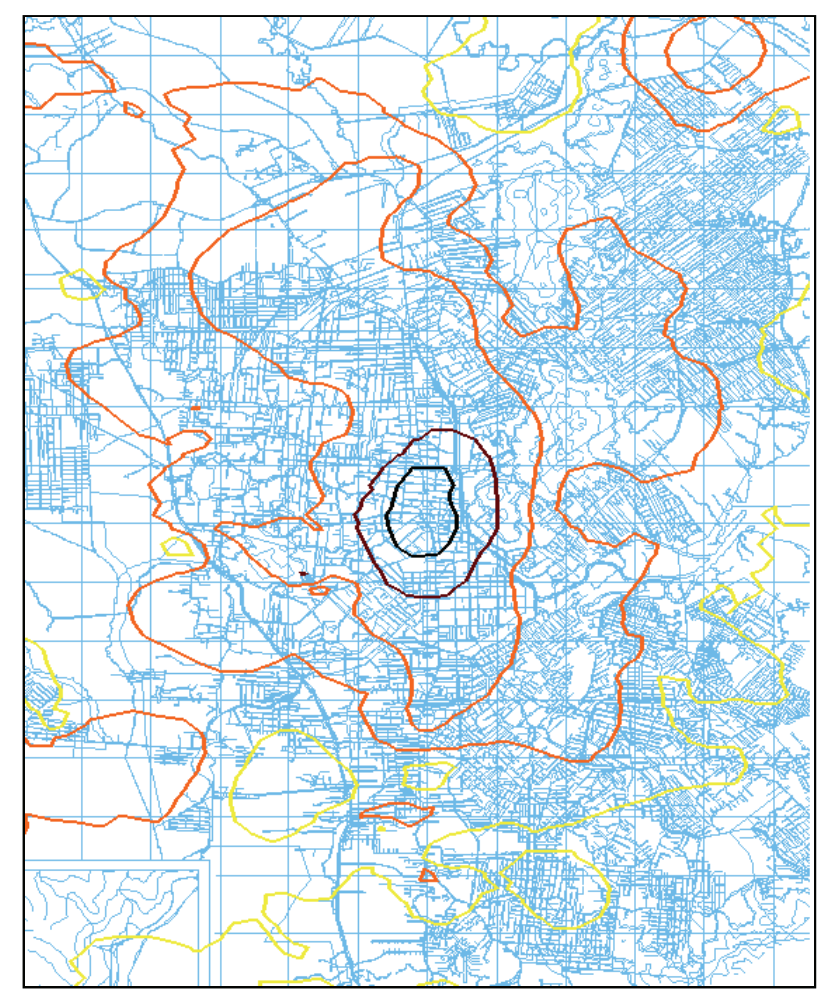

Figure 9. Real estate value estimated by LOOP/DP-DEA.

\section{REFERENCES}

[1] L. F. L. Novaes, "Double Perspective DEA in Real Estate Assessment with GIS," D.Sc. Thesis, Coppe/UFRJ, 2002, pp. 20-26.

[2] E. W. Eckard, "The Law of One Price in 1901," Economic Inquiry, Vol. 42, No. 1, 2004, pp. 101-110.

[3] T. K. Kuosmanen, L. Cherchye and T. Sipiläinen, "The Law of One Price in Data Envelopment Analysis: Restricting Weight Flexibility across Firms," European Journal of Operational Research, Vol. 170, No. 3, 2006, pp. 735-757.

[4] M. Baye, J. Morgan and P. Scholten, "Information, Search, and Price Dispersion," In: T. Hendershott, Ed., Handbook on Economics and Information Systems, Elsevier, Forthcoming, 2006.

[5] M. J. Farrell, "The Measurement of Productive Efficiency," Journal of the Royal Statistical Society, Series A, General, Part 3, Vol. 120, No. 3, 1957, pp. 253-281.

[6] A. Charnes, W. W. Cooper and Rhodes, "Measuring the Efficiency of Decision-Making Units," European Journal of Operational Research, Vol. 2, No. 6, 1978, pp. 429444.

[7] R. D. Banker, A. Charnes and W. W. Cooper, "Some Models for Estimating Technical and Scale Inefficiencies in Data Envelopment Analysis," Management Science, Vol. 30, No. 9, 1984, pp.1078-1092.

[8] R. Färe and G. Grosskopf, "Estimation of Returns to Scale Using Data Envelopment Analysis a Comment," European Journal of Operation Research, Vol.79, No. 2, 1994, pp. 379-382.

[9] M. E. Lins and L. A. Meza, "Data Envelopment Analysis and Integration Perspectives Decision Support Theory," Coppe/UFRJ, 2006, pp. 7-53.

[10] M. E. Lins, L. F. L. Novaes and L. F. L. Legey, "Real Estate Appraisal: A Double Perspective Data Envelopment Analysis Approach," Journal of Operational Research, Vol. 138, No. 1, 2005, pp. 79-96.

[11] G. Debreu, "Theory of Value: An Axiomatic Analysis of Economic Equilibrium," In: Cowles Foundation for Research in Economics of Yale University, 1959, pp. 28-79.

[12] Färe, R., G. Grosskopf and C. A. K. Lovell, "Production Frontiers," Cambridge University Press, Cambridge, 1996.

[13] R. Färe, C. A. K. Lovell and K. Zieschang, "Measuring the Technical Efficiency of Multiple Output Technologies”, W. Eichhorn, R. Henn, K. Neumann, Eds., 1983.

[14] R. W. Shephard, "Cost and Production Function," Princeton University Press, New Jersey, 1953.

[15] Software: EDODEA. http:www.avalsoft.com.br

[16] L. F. L.Novaes, M. E.Lins, S. A. Paiva and L. F. e Pinheiro Jr., "Avaliação Imobiliária Pelo Método da Envoltória sob Dupla Óptica," $3^{\circ}$ Simpósio Brasileiro de Engenharia de Avaliações, Curitiba, 2002.

[17] N. Cressie, "Statistics for Spatial Data," 1st Edition, Wiley InterScience, New York, 1991. 
[18] E. H. Isaaks and R. M. Shrivastava, "Applied Geostatis1989. tics," 1th Edition, Oxford University Press, New York, 